University of Louisville

ThinkIR: The University of Louisville's Institutional Repository

Electronic Theses and Dissertations

$5-2020$

\title{
Autism Spectrum Disorder: investigating predictive adaptive behavior skill deficits in young children.
}

Emma L. Feige

University of Louisville

Follow this and additional works at: https://ir.library.louisville.edu/etd

Part of the Speech Pathology and Audiology Commons

\section{Recommended Citation}

Feige, Emma L., "Autism Spectrum Disorder: investigating predictive adaptive behavior skill deficits in young children." (2020). Electronic Theses and Dissertations. Paper 3459.

https://doi.org/10.18297/etd/3459

This Master's Thesis is brought to you for free and open access by ThinkIR: The University of Louisville's Institutional Repository. It has been accepted for inclusion in Electronic Theses and Dissertations by an authorized administrator of ThinkIR: The University of Louisville's Institutional Repository. This title appears here courtesy of the author, who has retained all other copyrights. For more information, please contact thinkir@louisville.edu. 


\title{
AUTISM SPECTRUM DISORDER: INVESTIGATING PREDICTIVE ADAPTIVE
} BEHAVIOR SKILL DEFICITS IN YOUNG CHILDREN

\author{
By \\ Emma Feige \\ B.S.- Western Kentucky University, Bowling Green, KY, 2018 \\ A Thesis \\ Submitted to the Faculty of the \\ School of Medicine of the University of Louisville \\ in Partial Fulfillment of the Requirements \\ for the Degree of \\ Master of Science \\ in Communicative Disorders \\ Department of Otolaryngology and Head and Neck Surgery and Communicative \\ Disorders \\ University of Louisville \\ Louisville, Kentucky
}

May 2020 
(C) 2020

Emma Feige

All rights reserved 

AUTISM SPECTRUM DISORDER: INVESTIGATING PREDICTIVE ADAPTIVE BEHAVIOR SKILL DEFICITS IN YOUNG CHILDREN

\author{
By \\ Emma Feige \\ B.S.- Western Kentucky University, Bowling Green, KY, 2018 \\ A Thesis Approved on \\ April 10, 2020 \\ by the following Thesis Committee:
}

Teresa Pitts, Ph.D., Thesis Director

Alan F. Smith, Ed.D., Thesis Advisor

Rhonda Mattingly, Ed.D., Committee Member 


\section{DEDICATION}

To my sweet Stevie--thank you for showing me the world through a different lens. 


\section{ACKNOWLEDGMENTS}

I would like to offer my sincerest gratitude towards my thesis mentor Dr. Alan Smith, for his vast amount of time and effort he has poured into this project. Without his unwavering support and encouragement this thesis would not have been possible. I would also like to thank the rest of my thesis committee, Dr. Teresa Pitts and Dr. Rhonda Mattingly, for their consistent instruction and guidance throughout the past two years being in the program. Lastly, I would love to thank my mom, dad, fiancé and the rest of my amazing support system. They have instilled a confidence in me that will follow me in my future endeavors. 


\begin{abstract}
AUTISM SPECTRUM DISORDER: INVESTIGATING PREDICTIVE ADAPTIVE BEHAVIOR SKILL DEFICITS IN YOUNG CHILDREN
\end{abstract}

\author{
Emma Feige
}

April 10, 2020

Autism Spectrum Disorder (ASD) is a lifelong neurodevelopmental disorder that consists of difficulties with social communication and language, as well as the presence of restricted and repetitive behaviors. These deficits tend to present in early childhood and usually lead to impairments in functioning across various settings. Moreover, these deficits have been shown to negatively impact adaptive behavior and functioning. Thus, early diagnosis and intervention is vital for future success within this population. The purpose of this study was to further examine the subscales that comprise the adaptive behavior section of the Bayley ${ }^{\circledR}$-III to determine which of the ten subscales are predictive of ASD in young children (i.e., $\leq$ three years-of-age). A retrospective file review of 273 children participating in Kentucky's early intervention program, First Steps, was completed. The children ranged in age from 18-35 months. A binary logistic regression was used to assess the subscales that comprise the adaptive behavior of the section of the Bayley ${ }^{\circledR}$-III to determine which of the ten subscales are predictive of ASD in young children (i.e., $\leq$ three years-of-age). The results indicated that individual lower raw scores 
in communication, community use, functional pre-academics, home living, health and safety, leisure, self-care, self-direction, and social subscales were predictive of an autism diagnosis. 
TABLE OF CONTENTS

PAGE

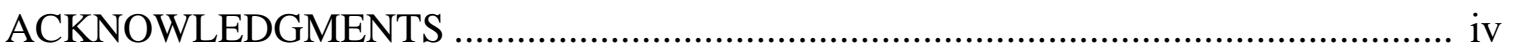

ABSTRACT .

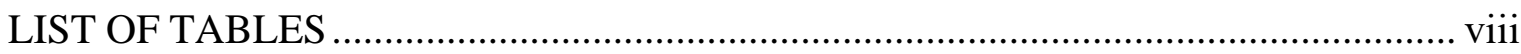

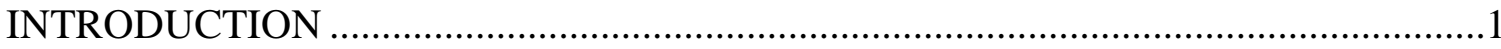

Research Hypotheses ...............................................................................12

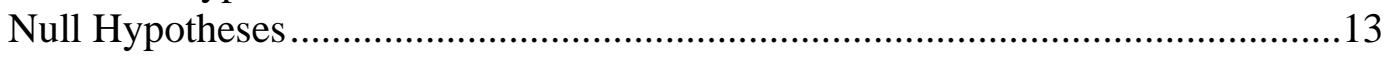

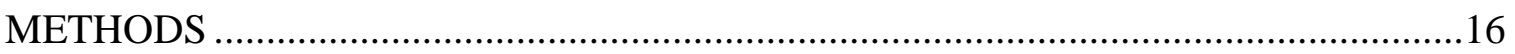

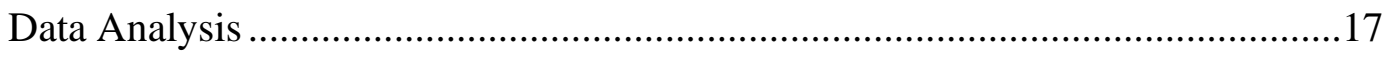

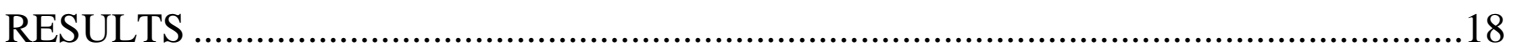

Logistic Regression Analyses .......................................................................20

Bayley®-III Adaptive Behavior Scale and ASD Diagnosis ..................................21

Bayley®-III Adaptive Behavior Communication Subscale and ASD Diagnosis...21

Bayley®-III Adaptive Behavior Community Use Subscale and ASD Diagnosis ..22

Bayley®-III Adaptive Behavior Pre-Academics Subscale and ASD Diagnosis....22

Bayley®-III Adaptive Behavior Home Living Subscale and ASD Diagnosis .......23

Bayley®-III Adaptive Behavior Health and Safety Subscale and ASD Diagnosis 23

Bayley®-III Adaptive Behavior Leisure Subscale and ASD Diagnosis .................23

Bayley®-III Adaptive Behavior Self-Care Subscale and ASD Diagnosis ..............24

Bayley®-III Adaptive Behavior Self-Direction Subscale and ASD Diagnosis .....24

Bayley $₫$-III Adaptive Behavior Social Subscale and ASD Diagnosis ...................24

Bayley®-III Adaptive Behavior Motor Subscale and ASD Diagnosis ...................25

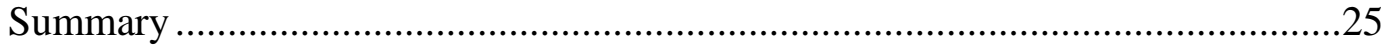

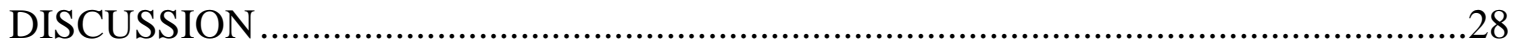

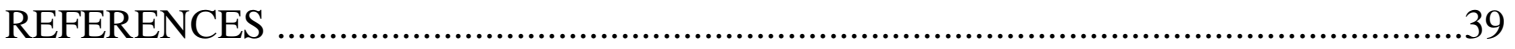

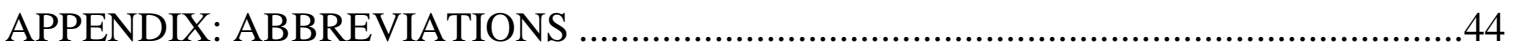

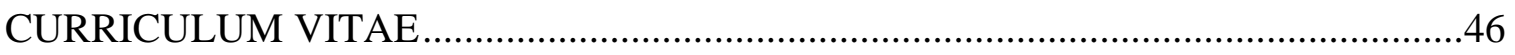




\section{LIST OF TABLES}

TABLE

PAGE

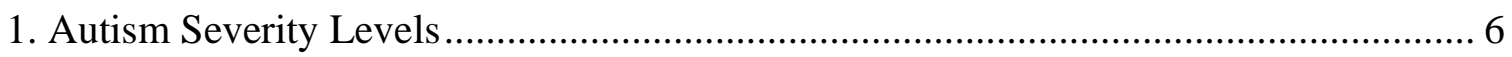

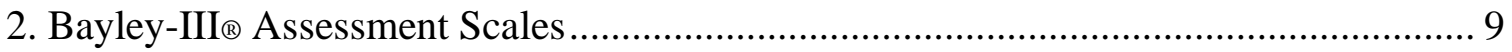

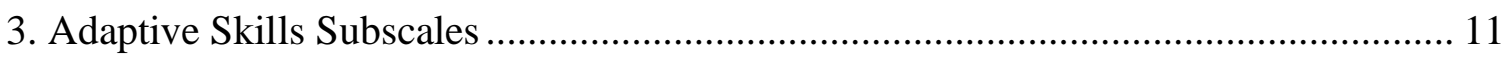

4. Descriptive Statistics Adaptive Behavior Subscale Raw Scores $(N=273) \ldots \ldots \ldots \ldots \ldots \ldots . . .18$

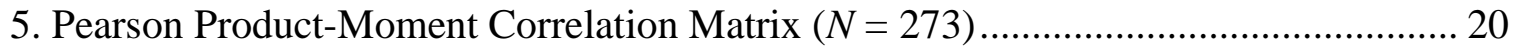

6. Predicting ASD Diagnosis Based on Adaptive Behavior Scale Standard Dev. .......... 21

7. Predicting ASD Diagnosis Based on Adaptive Behavior Subscale Raw Scores ......... 21

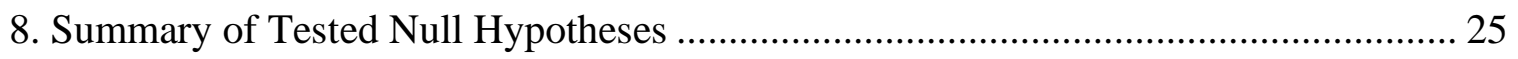




\section{CHAPTER 1}

\section{INTRODUCTION}

Autism Spectrum Disorder (ASD) is lifelong neurodevelopmental disorder that consists of deficits in social communication and language, as well as the presence of restricted and repetitive behaviors (American Psychiatric Association, 2013; Yates \& Le Couteur, 2016). ASD is described as a spectrum disorder as it presents differently in each individual. These deficits tend to present in early childhood and usually lead to impairments in functioning across various settings (Yates \& Le Couteur, 2016).

The first clinical account regarding autism was published by Dr. Leo Kanner in 1943. Kanner's (1943) research derived from his observations of 11 children and the follow study (1971) that demonstrated a condition characterized by lack of interest in the social world and behaviors he described as "insistence on sameness" (Kanner, 1943, p. 245; Volkmar \& Reichow, 2013). With the accumulation of research there was strong evidence to support inclusion of autism as a new condition in the Diagnostic and Statistical Manual of Mental Disorders-3rd edition (DSM-III) published in the late 1970's (American Psychiatric Association, 1985; Volkmar \& Reichow, 2013). In the DSM-III, autism was included under the class of conditions called pervasive developmental disorders (PDD) (American Psychiatric Association, 1985). At the time, autism was characterized by impaired social development, impaired communication and language skills, resistance to change or insistence of sameness, and onset within the first five years of life (American Psychiatric Association, 1985). 
With the publication of DSM-IV in 1994, changes were made based on sensitivity and specificity of the characteristics of this condition and improved reliability (American Psychiatric Association, 1994; Volkmar \& Reichow, 2013). Autism continued to be included under the classification of PDD with an additional 3 disorders (American Psychiatric Association, 1994). PDD class of conditions now included: autistic disorder, Asperger's disorder, Rett's disorder, childhood disintegrative disorder and pervasive developmental disorder not otherwise specified (PDD-NOS) (American Psychiatric Association, 1994). Specific characteristics of autism included in the DSM-IVTR consisted of: impairment in social interaction, impairments in communication, restricted, repetitive and stereotyped pattern of behaviors, interests, and activities, and delays or abnormal functioning in language, play and social interactions with an onset prior to three years of age (American Psychiatric Association, 1994). Revisions were made in the publication of the DSM-V by replacing the classification of PDD with Autism Spectrum Disorder (ASD) (American Psychiatric Association, 2013). The conditions previously classified under PDD are now termed ASD (American Psychiatric Association, 2013). The DSM-V defines ASD as a heterogeneous group of disorders characterized by current and/or historical deficits in social communication and the presence of repetitive behaviors that limit and impair everyday functioning (American Psychiatric Association, 2013).

The Centers for Disease Control and Prevention reports that approximately 1 in 59 children are diagnosed with ASD crossing all racial, ethnic, and socioeconomic groups (Baio et al., 2018). Previous research has reported a steady increase in the prevalence of ASD over the past 2 decades (Xu, Strathearn, Liu, \& Bao, 2018). Probable reasons for the 
increase include the "broadening of diagnostic criteria and improved case recognition" (Yates \& Le Couteur, 2016, p. 513). Moreover, symptomology of ASD tends to present differently in males and females (Yates \& Le Couteur, 2016). "Camouflaging theory" suggests that females may "mask socio-communicative impairments due to increased sensitivity to social pressure to fit in, gendered expectations for social behavior, and strengths in some social-communication skills" (Ratto et al., 2018, p. 1711). This could result in females possibly being "missed by current diagnostic procedures" (Ratto et al., 2018, p. 1698). Nonetheless, diagnosis of ASD appears to be 4 times more common in males than in females (Baio et al., 2018).

Secondary to the "heterogeneity of affected individuals and the genetic complexity" of the disorder, it has been difficult to identify the cause(s) of ASD (Yates \& Le Couteur, 2016, p. 55). Previous research has suggested several possible etiologies; however, the literature remains inconclusive. Bölte, Girdler, and Marschik (2019) suggest that many genetic and environmental factors and their interactions may contribute to autism phenotypes, but their specific causal mechanisms remain poorly understood. Inasmuch, Yates and Le Couteur (2016) suggest that significant genetic variations have been found in approximately $10 \%$ of individuals diagnosed with ASD. Increased paternal and maternal age has also been associated with higher risk of having a child with autism, possibly due to "de novo spontaneous mutations and/or alterations in genetic imprinting" (Johnson, Myers, \& American Academy of Pediatrics Council on Children With, 2007, p. 1186). Moreover, strong heritability has been linked with ASD as recurrence rates for siblings has been reported to be up to 18.7\% (Yates \& Le Couteur, 2016). "Research continues to study neurobiological 
differences in ASD considering variation in neurotransmitters, volumetric and functioning differences of various regions within the brain, but the relevance to clinical practice of most identified abnormalities has not been established" (Yates \& Le Couteur, 2016, p. 55).

Environmental factors may also play in a role in possible ASD diagnosis. AlHamdan, Preetha, Albashaireh, Al-Hamdan, and Crosson (2018, p. 7925) found that exposure to environmental neurotoxicants during prenatal, natal and postnatal development has been shown to influence the biochemical brain development, resulting in "neurodevelopmental abnormalities that may contribute to ASD". More specifically, prenatal exposures to "air pollution, heavy metals, pesticides and toxic substances in consumer products" could bring about atypical brain development, resulting in possible neural pathologies such as ASD (Wong, Wais, \& Crawford, 2015). Through growing research, it has become more evident that the etiology associated with ASD is multifactorial with genetic and environmental factors playing a role (Johnson et al., 2007).

The heterogeneity of ASD is evident in the early years of development as well (Matson, Wilkins, \& Fodstad, 2010; Werner, Dawson, Munson, \& Osterling, 2005). Kanner first described autism as being one of an "infantile" type, suggesting that the onset of symptoms occurred throughout the early ages of life (Johnson et al., 2007). Another study examined three possible types/developmental trajectories of ASD in children (Barbeau, 2017). These three types include: early onset, regression and plateau (Barbeau, 2017). ASD symptoms manifest soon after birth in children with the early onset type, whereas children with the regressive type begin to develop normally 
until around two years of age proceeded by a regression in development (Barbeau, 2017). This regression is most evident in the child's language and social skills (Barbeau, 2017). Lastly, children with the plateau type, develop normally until approximately six months of age and cease to make any developmental advances (Barbeau, 2017). For example, Rogers (2004, p. 140) describes a halting of development where "babbling was present, but did not continue to develop into speech”. Regarding ongoing development and future outcomes, evidence suggests that children who present with the regressive developmental trajectory tend to have more severe deficits across time and in a variety of areas (Matson et al., 2010; Rogers, 2004).

The DSM-V (American Psychiatric Association, 2013) provides the current diagnostic criteria for diagnosing individuals with ASD. The symptoms include: 1. persistent deficits in social communication and interaction across all contexts (via current and/or historical report),

2. presence of restricted and repetitive patterns of behaviors, interests or activities (via current and/or historical report),

3. symptoms must be present during early childhood,

4. symptoms together limit and impair everyday social, occupational or other aspects of current functioning, and

5. the deficits are not better explained by intellectual disability or global developmental delay.

The DSM-V further identifies severity levels of ASD ranging from level 1 (requires support) to level 3 (requires very substantial levels of support). The levels as 
reported on the Autism Speaks website (and used with permission by the American

Psychiatric Association) are included in the following table

\section{Table 1}

Autism Severity Levels

\begin{tabular}{|c|c|c|}
\hline Severity & Social Communication & $\begin{array}{l}\text { Restricted and Repetitive } \\
\text { Behaviors }\end{array}$ \\
\hline $\begin{array}{l}\text { Level } 3 \\
\text { "Requiring } \\
\text { very } \\
\text { substantial } \\
\text { support" }\end{array}$ & $\begin{array}{l}\text { Severe deficits in verbal and } \\
\text { nonverbal social } \\
\text { communication skills cause } \\
\text { severe impairments in } \\
\text { functioning, very limited } \\
\text { initiation of social interactions, } \\
\text { and minimal response to social } \\
\text { overtures from others. For } \\
\text { example, a person with few } \\
\text { words of intelligible speech } \\
\text { who rarely initiates interaction } \\
\text { and, when he or she does, make } \\
\text { unusual approaches to meet } \\
\text { needs only and responds to } \\
\text { only very direct social } \\
\text { approaches }\end{array}$ & $\begin{array}{l}\text { Inflexibility of behavior, } \\
\text { extreme difficulty coping } \\
\text { with change, or other } \\
\text { restricted/repetitive } \\
\text { behaviors } \\
\text { markedly interfere with } \\
\text { functioning in all spheres. } \\
\text { Great distress/difficulty } \\
\text { changing focus or action }\end{array}$ \\
\hline $\begin{array}{l}\text { Level } 2 \\
\text { "Requiring } \\
\text { substantial } \\
\text { support" }\end{array}$ & $\begin{array}{l}\text { Marked deficits in verbal and } \\
\text { nonverbal social communication } \\
\text { skills; social impairments } \\
\text { apparent even with supports in } \\
\text { place; limited initiation of social } \\
\text { interactions; and reduced or } \\
\text { abnormal responses to social } \\
\text { overtures from others. For } \\
\text { example, a person who speaks } \\
\text { simple sentences, whose } \\
\text { interaction is limited to narrow } \\
\text { special interests, and how has } \\
\text { markedly odd nonverbal } \\
\text { communication }\end{array}$ & $\begin{array}{l}\text { Inflexibility of behavior, } \\
\text { difficulty coping with } \\
\text { change, or other } \\
\text { restricted/repetitive } \\
\text { behaviors appear frequently } \\
\text { enough to be obvious to the } \\
\text { casual observer and } \\
\text { interfere with functioning } \\
\text { in a variety of contexts. } \\
\text { Distress and/or difficulty } \\
\text { changing focus or action. }\end{array}$ \\
\hline Level 1 & $\begin{array}{l}\text { Without supports in place, } \\
\text { deficits in social communication }\end{array}$ & $\begin{array}{l}\text { Inflexibility of behavior } \\
\text { causes significant }\end{array}$ \\
\hline
\end{tabular}


"Requiring support" cause noticeable impairments.

Difficulty initiating social interactions, and clear examples of atypical or unsuccessful response to social overtures of others. For example, a person who is able to speak in full sentences and engages in communication but whose toand-fro conversation with others fails, and whose attempts to make friends are off and typically unsuccessful

(Autism Speaks, n.d.)

interference with functioning in one or more contexts. Difficulty switching between activities. Problems of organization and planning hamper independence.

While the DSM-V provides guidelines and criteria—including severity levelsfor diagnosing ASD, it also highlights the fact that symptoms must also be present during early childhood. Under the Individuals with Disabilities Education Act (IDEA), specifically Part C, the law defines the age range for children eligible for early intervention serves as birth-to-three years of age (U.S. Department of Education, 2004). The American Speech-Language-Hearing Association defines early intervention as providing families, toddler and infants who have or are at-risk of a developmental delay, disability or other health condition that inhibits typical development with intervention services.

Evidence suggests that the earlier a child receives intervention, the greater the likelihood of an improved developmental trajectory (Koegel, Koegel, Ashbaugh, \& Bradshaw, 2014). In general, intensive intervention implemented before age three has been associated with better communicative, academic and behavioral outcomes at school age (Owens, 2017). Several studies have concluded that children with autism make greater gains in intervention when it begins earlier, between the ages of two 
and four, as compared to older children receiving the same interventions, including those with other neurodevelopmental disorders (Rogers, 1996). More recent emerging evidence supports the idea that earlier and more intensive treatment results in more favorable outcomes (Pasco, 2018).

Early intervention services often address the needs of children across five developmental areas, including: cognitive, motor, social-emotional, communication and adaptive development (U.S. Department of Education, 2004). Children referred for early intervention services typically undergo an in-depth evaluation process to assess their therapeutic needs prior to intervention. Various assessment measures may be used during this process with differing requirements from state-to-state. Nonetheless, the assessment process should be comprised of a comprehensive set of activities to (1) identify a child's strengths and weaknesses, (2) address the families concerns and priorities, and (3) develop a plan for ongoing treatment strategies for the child (Crais, 2011; Raver \& Childress, 2015)

IDEA requires that the evaluation/assessment be completed using a range of tools in a variety of contexts (U.S. Department of Education, 2004). The instruments used may include both criterion-referenced and/or standardized properties. One tool, in particular, that is often utilized within early intervention circles is the Bayley Scales of Infant and Toddler Development $₫$ (3rd Edition) or the Bayley®-III. The Bayley®-III is a comprehensive assessment tool used to identify developmental issues in early childhood (Bayley, 2006). The battery encompasses the aforementioned five developmental domains mandated by IDEA and are described in the table below (U.S. Department of Education, 2004). 


\section{Table 2}

Bayley-III $\circledast$ Assessment Scales

\begin{tabular}{ll}
\hline $\begin{array}{l}\text { Scales } \\
\text { Cognitive Scale }\end{array}$ & $\begin{array}{l}\text { Scales Explained (Bayley, 2006) } \\
\text { Assesses sensorimotor development, exploration and } \\
\text { manipulation, object relatedness, concept } \\
\text { formation, memory, and other aspects of cognitive processing }\end{array}$ \\
$\begin{array}{l}\text { Language Scale } \\
\text { Receptive Language }\end{array}$ & $\begin{array}{l}\text { Assesses preverbal behaviors, such as vocabulary development, } \\
\text { understanding of morphological markers, social referencing, } \\
\text { and verbal comprehension }\end{array}$ \\
Expressive Language & $\begin{array}{l}\text { Assesses the preverbal communication, such as babbling, } \\
\text { gesturing, joint referencing, turn taking, and morpho-syntactic } \\
\text { development }\end{array}$
\end{tabular}

Motor Scale

Fine Motor

Assesses prehension, perceptual-motor integration, motor planning and motor speed

Gross Motor Measures the movement of the limbs and torso

Social-

Emotional Scale

Assesses child's mastery of functional emotional skills, such as self-regulation and interest in the word; communicating needs; engaging others and establishing relationships; using emotions in an interactive, purposeful manner; and using emotional signals or gestures to solve problems

Adaptive Behavior Assesses the child's daily functional skills Scale

Previous research has shown that individual lower subscale scores within the cognitive, language, adaptive behavior, and social-emotional developmental domains on the Bayley®-III were predictive of an ASD diagnosis in children three years of age and younger (Juergensen, Smith, Mattingly, \& Pitts, 2018). Due to current literature and ASD 
diagnostic criteria, this outcome is not surprising with regards to language and socialemotional domains. A direct connection with the cognitive and adaptive behavior sections; however, may be less clear.

Adaptive behavior appears strongly associated with intelligence in neurotypical individuals; however, "cognitively able individuals with ASD fail to acquire adaptive skills at rates corresponding with gains" in intelligence (Pugliese et al., 2015, p. 467). Moreover, the "gap in daily living skills (i.e., adaptive skills) between children with ASD and typically developing children increased across early childhood" (Pugliese et al., 2015, p. 468) including poorer planning abilities and cognitive flexibility (Phung \& Goldberg, 2019). Nonetheless, a review of the literature examining ASD and adaptive functioning conclude that individuals with ASD tend to present with adaptive functioning difficulties as compared to their same-age peers (Kanne et al., 2011; Pugliese et al., 2015; White et al., 2017).

Harrison and Oakland (2003, p. 5), define adaptive behavior skills as "practical, everyday skills needed to function and meet the demands of one's environment, including the skills necessary to effectively and independently take care of oneself and to interact with other people". Within the subscale of the adaptive behavior skills portion of the Bayley®-III, there are ten subscales. The subscales are comprised of: communication, community use, functional pre-academics, home living, health and safety, leisure, selfcare, self-direction, social, and motor (Bayley, 2006). These subscales "assess the daily functional skills of a child, measuring what the child actually does, in addition to what he or she may be able to do" (Bayley, 2006, p. 4). Scores are provided via parent report and are based on the frequency (e.g., is not able, never when needed, sometimes when 
needed, always when needed) with which the child performs the behavior when it is needed and without help provided (Bayley, 2006). The following table lists the targeted adaptive behaviors from the Bayley®-III and then defines the skill.

\section{Table 3}

Adaptive Skills Subscales

\begin{tabular}{ll}
\hline Adaptive Skill Subscales & Subscales Explained (Bayley, 2006) \\
\hline Communication (Com) & $\begin{array}{l}\text { Assesses child's speech, language, listening, and } \\
\text { nonverbal communication skills (Bayley, 2006) }\end{array}$ \\
Community Use (CU) & $\begin{array}{l}\text { Assesses child's interest in activities outside the home } \\
\text { and recognition of different facilities (Bayley, 2006). }\end{array}$ \\
$\begin{array}{l}\text { Functional Pre-Academics } \\
\text { (FA) }\end{array}$ & $\begin{array}{l}\text { Assesses child's abilities for letter recognition, } \\
\text { counting, and drawing simple shapes (Bayley, 2006). }\end{array}$ \\
Home Living (HL) & $\begin{array}{l}\text { Assesses child's abilities in helping adults with } \\
\text { household tasks and taking care of personal } \\
\text { possessions (Bayley, 2006). }\end{array}$ \\
Health and Safety (HS) & $\begin{array}{l}\text { Assesses child's abilities in showing caution and } \\
\text { keeping out of physical danger (Bayley, 2006). }\end{array}$ \\
Leisure (LS) & $\begin{array}{l}\text { Assesses child's abilities in playing, following rules, } \\
\text { and engaging in recreation at home (Bayley, 2006). }\end{array}$ \\
Self-Care (SC) & $\begin{array}{l}\text { Assesses child's eating, toileting, and bathing skills } \\
\text { (Bayley, 2006). }\end{array}$ \\
Social (Soc) & $\begin{array}{l}\text { Assesses child's abilities in self-control, following } \\
\text { directions, and making choices (Bayley, 2006). }\end{array}$ \\
assesses child's abilities in getting along with other \\
people, such as, using manners, assisting others, and \\
environment (Bayley, 2006).
\end{tabular}


The purpose of the study was to further examine the subscales that comprise the adaptive behavior section of the Bayley®-III to determine which of the ten subscales are predictive of ASD in young children (i.e., $\leq$ three years-of-age). Improved knowledge of the predictive value of each subscale, or combination thereof, may contribute to an improved understanding of the role adaptive behavior plays in the diagnosis of ASD.

\section{Research Hypotheses}

The research hypotheses are as follows:

$\mathrm{H}_{1}$ : There will be a statistically significant association between autism spectrum disorder diagnosis in children $\leq$ three years-of-age and their adaptive behavior domain standard deviation subscale score on the Bayley®-III.

$\mathrm{H}_{1 \mathrm{a}}$ The communication subscale raw score on the Bayley®-III will significantly contribute to the variance in predicting autism spectrum disorder diagnosis in children $\leq$ three years-of-age.

H1b: The community use subscale raw score on the Bayley®-III will significantly contribute to the variance in predicting autism spectrum disorder diagnosis in children $\leq$ three years-of-age.

H1c: The functional pre-academics subscale raw score on the Bayley®-III will significantly contribute to the variance in predicting autism spectrum disorder diagnosis in children $\leq$ three years-of-age.

H1d: The home living subscale raw score on the Bayley®-III will significantly contribute to the variance in predicting autism spectrum disorder diagnosis in children $\leq$ three years-of-age. 
H1e: The health and safety subscale raw score on the Bayley®-III will significantly contribute to the variance in predicting autism spectrum disorder diagnosis in children $\leq$ three years-of-age.

H1f: The leisure subscale raw score on the Bayley®-III will significantly contribute to the variance in predicting autism spectrum disorder diagnosis in children $\leq$ three yearsof-age.

H1g: The self-care subscale raw score on the Bayley®-III will significantly contribute to the variance in predicting autism spectrum disorder diagnosis in children $\leq$ three years-of-age.

H1h: The self-direction subscale raw score on the Bayley®-III will significantly contribute to the variance in predicting autism spectrum disorder diagnosis in children $\leq$ three years-of-age.

$\mathrm{H}_{1 i}$ : The social subscale raw score on the Bayley®-III will significantly contribute to the variance in predicting autism spectrum disorder diagnosis in children $\leq$ three yearsof-age.

$\mathrm{H}_{1 \mathrm{j}}$ : The motor subscale raw score on the Bayley®-III will significantly contribute to the variance in predicting autism spectrum disorder diagnosis in children $\leq$ three yearsof-age.

\section{Null Hypotheses}

The null hypotheses are as follows:

$\mathrm{H}_{1}$ : There will not be a statistically significant association between autism spectrum disorder diagnosis in children $\leq$ three years-of-age and their adaptive behavior domain standard subscale score on the Bayley®-III. 
$\mathrm{H}_{1 \mathrm{a}}$ The communication subscale raw score on the Bayley®-III will not significantly contribute to the variance in predicting autism spectrum disorder diagnosis in children $\leq$ three years-of-age.

H1b: The community use subscale raw score on the Bayley®-III will not significantly contribute to the variance in predicting autism spectrum disorder diagnosis in children $\leq$ three years-of-age.

H1c: The functional pre-academics subscale raw score on the Bayley®-III will not significantly contribute to the variance in predicting autism spectrum disorder diagnosis in children $\leq$ three years-of-age.

H1d: The home living subscale raw score on the Bayley®-III will not significantly contribute to the variance in predicting autism spectrum disorder diagnosis in children $\leq$ three years-of-age.

H1e: The health and safety subscale raw score on the Bayley®-III will not significantly contribute to the variance in predicting autism spectrum disorder diagnosis in children $\leq$ three years-of-age.

H1f: The leisure subscale raw score on the Bayley®-III will not significantly contribute to the variance in predicting autism spectrum disorder diagnosis in children $\leq$ three years-of-age.

H1g: The self-care subscale raw score on the Bayley®-III will not significantly contribute to the variance in predicting autism spectrum disorder diagnosis in children $\leq$ three years-of-age. 
H1h: The self-direction subscale raw score on the Bayley®-III will not significantly contribute to the variance in predicting autism spectrum disorder diagnosis in children $\leq$ three years-of-age.

$\mathrm{H}_{11}$ : The social subscale raw score on the Bayley®-III will not significantly contribute to the variance in predicting autism spectrum disorder diagnosis in children $\leq$ three years-of-age.

$\mathrm{H}_{1 \mathrm{j}}$ : The motor subscale raw score on the Bayley®-III will not significantly contribute to the variance in predicting autism spectrum disorder diagnosis in children $\leq$ three years-of-age. 


\section{CHAPTER 2}

\section{METHODS}

This study utilized a retrospective file review of children $(N=273)$ that participated in Kentucky's early intervention program, First Steps, between 1/1/2012 and 6/1/2019. The sample included children between the ages of 18-35 months and comprised 203 males and 70 females. Tabachnick and Fidell (2013) recommend a sample size of at least 80 where $N>50+8 m$ ( $m$ is the number of predictor variables). Moreover, Babyak (2004) suggested a minimum sample size of 10-15 observations per predictor variable. Children with and without ASD diagnosis were represented. ASD diagnosis was determined by Intensive Level of Evaluation (ILE) as completed by the University of Louisville Weisskopf Child Evaluation Center (WCEC). For the purpose of this study, an ILE is equivalent to a multidisciplinary evaluation that typically involves-in Kentucky—a Speech-Language Pathologist, Psychologist, and Developmental Pediatrician. An Occupational Therapist may also be involved on a case-by-case basis. Approval for this study was granted by the Institutional Review Boards (IRB) of the University of Louisville and the Kentucky Cabinet for Health and Family Services.

The researchers were granted access to the Technology-assisted Observation and Teaming Support (TOTS) database, an electronic record used by the Kentucky Department of Public Health to track children as they are referred, evaluated, and-in some cases—receive services through the early intervention program. The researchers 
used TOTS to query children referred to — and evaluated by—First Steps between the aforementioned date range. Specific interest centered on ASD diagnosis. Demographic information included each child's age (in months) at evaluation and gender. Paper-based files were reviewed at the Kentuckiana Point of Entry office. The Bayley-III protocols were pulled from each file (for children diagnosed as having ASD) and randomly for children with developmental delay. The raw scores for the ten adaptive behavior subsections and the overall standard deviation scores for the overall adaptive behavior section were anonymously compiled into a Microsoft Excel spreadsheet and then exported to IBM SPSS for Windows, version 25 (IBM Corp., Armonk, N.Y., USA) for statistical analyses. Separate spreadsheets were created for children diagnosed with ASD and those that did not carry the diagnosis. The "cleaned" data was stored on a password protected computer behind a locked door; a master-code was never created. Gender was coded where $1=$ male and $2=$ female. ASD diagnosis was coded in the same manner where $1=$ not diagnosed and $2=$ diagnosed. No identifying information was recorded.

\section{Data Analysis}

A binary logistic regression was used to assess the subscales that comprise the adaptive behavior section of the Bayley®-III to determine which of the ten subscales (e.g., communication, community use, functional pre-academics, home living, health and safety, leisure, self-care, self-direction, social, and motor) are predictive of ASD in young children (i.e., $\leq$ three years-of-age). A binary logistic regression analysis was used, as the criterion variable—ASD diagnosis—is dichotomous (Warner, 2013). Descriptive statistics, assumption testing, and the results of the logistic regression analyses are provided in Chapter 3. 


\section{CHAPTER 3}

\section{RESULTS}

This study comprised a retrospective file review of 273 children in the state of Kentucky; $74.4 \%(n=203)$ were male and $25.6 \%(n=70)$ were female. The ages ranged from 18 -35 months $(M=24.04, S D=5.30)$. Forty-eight percent $(n=131)$ of the children were diagnosed with ASD; 52\% $(n=142)$ did not have an ASD diagnosis.

Table 4 presents the mean and standard deviations for the ten subscales of the adaptive behavior section of the Bayley-III (Bayley, 2006). Consistent with regressionbased analyses, the ten subscales are referenced as predictor variables. ASD diagnosis served as the criterion variable.

\section{Table 4}

Descriptive Statistics Adaptive Behavior Subscale Raw Scores $(N=273)$

\begin{tabular}{lcc}
\hline Subscale & $M$ & $S D$ \\
\hline Communication & 25.0 & 10.0 \\
Community Use & 9.6 & 8.4 \\
Functional Pre-Academics & 6.6 & 7.9 \\
Home Living & 22.7 & 15.3 \\
Health and Safety & 23.6 & 11.5 \\
Leisure & 28.5 & 10.2 \\
Self-Care & 35.8 & 9.4 \\
Self-Direction & 29.1 & 11.0 \\
Social & 31.6 & 10.0 \\
Motor & 51.5 & 11.0 \\
\hline
\end{tabular}

Logistic regressions are sensitive to multicollinearity. Multicollinearity occurs when two or more predictor variables are highly correlated, meaning one variable can be 
linearly predicted from the other variables with a relatively high level of accuracy. It is not uncommon to have issues with multicollinearity using subscales from the same measure. When multicollinearity is a concern, centering the variables may correct the issue.

"When data are not centered, the regression coefficients that are estimated and tested may be irrelevant and misleading. Centering, thoughtfully done, can diminish the almost inevitable multicollinearity problems in regression, thus increasing both the precision of parameter estimation and the power of statistical testing of those parameters (Kraemer \& Blasey, 2004, p. 142).”

As previously suggested, the continuous variables were mean centered by subtracting the mean from the value for each variable. The dichotomous variable-ASD diagnosis - was also centered. This was completed by changing the values of 0 to -.5 and 1 to .5 . Variables were centered as a strategy to prevent errors in statistical inference.

A correlation matrix (Pearson) was calculated to assess multicollinearity presence. Mukaka (2012) was used to interpret the size of the correlation coefficient. Tabachnick and Fidell (2013) suggest that as long as correlation coefficients among independent variables are less than 0.90 multicollinearity is less likely to have occurred. The results are presented in Table 5 


\section{Table 5}

Pearson Product-Moment Correlation Matrix $(N=273)$

\begin{tabular}{lllllllllll}
\hline & ADP & CO & CU & FA & HL & HS & LS & SC & SD & SOC \\
\hline ADP & & & & & & & & & & \\
CO & .57 & & & & & & & & & \\
CU & .47 & .56 & & & & & & & & \\
FA & .36 & .55 & .49 & & & & & & & \\
HL & .51 & .59 & .72 & .49 & & & & & & \\
HS & .44 & .62 & .61 & .40 &. $\mathbf{7 8}$ & & & & & \\
LS & .55 & .64 & .49 & .41 & .64 & .68 & & & & \\
SC & .42 & .58 & .49 & .26 & .63 & .69 &. $\mathbf{7 4}$ & & & \\
SD & .49 & .54 & .57 & .29 & $\mathbf{. 7 0}$ &. $\mathbf{7 5}$ & $\mathbf{. 8 1}$ &. $\mathbf{7 4}$ & & \\
SOC & .59 & .76 & .57 & .44 & $\mathbf{. 7 0}$ &. $\mathbf{7 0}$ &. $\mathbf{7 6}$ &. $\mathbf{7 0}$ &. $\mathbf{7 5}$ & \\
MO & .17 & .40 & .45 & .23 & .60 & .68 & .61 & .64 & .67 & .62 \\
\hline
\end{tabular}

Moderate Positive (Negative) Correlation $|r=.50-.70|$ in italics .

High Positive (Negative) Correlation $|r>.70|$ in bold.

\section{Logistic Regression Analyses}

Individual logistic regression analyses were used to examine the relationship between the overall adaptive behavior scale and the associated subscale raw scores with the diagnosis of ASD. Logistic regression allows the use of outcome variables that are categorical and predictor variables that are continuous or categorical. Logistic regression analysis is the most appropriate statistical measure since the criterion variable is

dichotomous. Table 6 shows the results of the logistic regression analysis examining the overall adaptive behavior scale as a predictor of ASD. The complete results of the logistic regression analyses for the individual subscales that comprise the adaptive behavior scale are presented in Table 7. 


\section{Table 6}

Predicting ASD Diagnosis Based on Adaptive Behavior Scale Standard Dev.

\begin{tabular}{lcccc}
\hline Subscale & Odds Ratio & $95 \%(\mathrm{CI})$ & $\%$ Variance & $p$ \\
\hline Adaptive Behavior & .12 & $.08-.20$ & $53 \%$ & $<.001$ \\
\hline
\end{tabular}

\section{Table 7}

Predicting ASD Diagnosis Based on Adaptive Behavior Subscale Raw Scores

\begin{tabular}{lcccc}
\hline Subscale & Odds Ratio & $95 \%(\mathrm{CI})$ & $\%$ Variance & $p$ \\
\hline Communication & .86 & $.83-.90$ & $34 \%$ & $<.001$ \\
Community Use & .91 & $.88-.95$ & $15 \%$ & $<.001$ \\
Pre-Academics & .93 & $.89-.97$ & $8 \%$ & $<.001$ \\
Home Living & .96 & $.94-.98$ & $11 \%$ & $<.001$ \\
Health/Safety & .95 & $.93-.98$ & $9 \%$ & $<.001$ \\
Leisure & .92 & $.89-.95$ & $18 \%$ & $<.001$ \\
Self-Care & .93 & $.90-.96$ & $13 \%$ & $<.001$ \\
Self-Direction & .95 & $.92-.97$ & $10 \%$ & $<.001$ \\
Social & .88 & $.85-.91$ & $31 \%$ & $<.001$ \\
Motor & .98 & $.96-1.01$ & $1 \%$ & .14 \\
\hline
\end{tabular}

Bayley®-III Adaptive Behavior Scale and ASD Diagnosis

Logistic regression - step 1 - entered the adaptive behavior scale standard

deviation scores as a predictor of ASD diagnosis. The results were statistically significant (odds ratio $=.12,95 \% \mathrm{CI}=.08-.20, p<.001)$ and explained 53\% (Nagelkereke $R 2)$ of the variance of ASD diagnosis. The results suggest that children who receive lower standard deviation scores on the Bayley®-III adaptive behavior scale are more likely to receive an ASD diagnosis than children with higher standard deviation scores.

Bayley®-III Adaptive Behavior Communication Subscale and ASD Diagnosis Logistic regression - step 1a-entered the adaptive behavior communication subscale raw scores as a predictor of ASD diagnosis. The results were statistically 
significant (odds ratio $=.86,95 \% \mathrm{CI}=.83-.90, p<.001)$ and explained $34 \%$

(Nagelkereke $R_{2}$ ) of the variance of ASD diagnosis. The results suggest that children who scored lower (raw scores) on the communication subscale on the Bayley ${ }_{\circledR}$-III adaptive behavior scale are more likely to receive an ASD diagnosis than children with higher communication subscale raw scores.

Bayley®-III Adaptive Behavior Community Use Subscale and ASD Diagnosis Logistic regression — step $1 \mathrm{~b}$ —entered the adaptive behavior community use subscale raw scores as a predictor of ASD diagnosis. The results were statistically significant (odds ratio $=.91,95 \% \mathrm{CI}=.88-.95, p<.001)$ and explained $15 \%$ (Nagelkereke $R_{2}$ ) of the variance of ASD diagnosis. The results suggest that children who scored lower (raw scores) on the community use subscale on the Bayley®-III adaptive behavior scale are more likely to receive an ASD diagnosis than children with higher community use subscale raw scores.

Bayley®-III Adaptive Behavior Pre-Academics Subscale and ASD Diagnosis Logistic regression — step 1c —entered the adaptive behavior functional preacademics subscale raw scores as a predictor of ASD diagnosis. The results were statistically significant (odds ratio $=.93,95 \% \mathrm{CI}=.89-.97, p<.001$ ) and explained $8 \%$ (Nagelkereke $R_{2}$ ) of the variance of ASD diagnosis. The results suggest that children who scored lower (raw scores) on the functional pre-academics subscale on the Bayley®-III adaptive behavior scale are more likely to receive an ASD diagnosis than children with higher functional pre-academics subscale raw scores. 
Bayley®-III Adaptive Behavior Home Living Subscale and ASD Diagnosis Logistic regression—step $1 \mathrm{~d} —$ entered the adaptive behavior home living subscale raw scores as a predictor of ASD diagnosis. The results were statistically significant (odds ratio $=.96,95 \% \mathrm{CI}=.94-.98, p<.001)$ and explained $11 \%($ Nagelkereke $R 2)$ of the variance of ASD diagnosis. The results suggest that children who scored lower (raw scores) on the home living subscale on the Bayley®-III adaptive behavior scale are more likely to receive an ASD diagnosis than children with higher home living subscale raw scores.

Bayley®-III Adaptive Behavior Health and Safety Subscale and ASD Diagnosis Logistic regression — step 1e - entered the adaptive behavior health and safety subscale raw scores as a predictor of ASD diagnosis. The results were statistically significant (odds ratio $=.95,95 \% \mathrm{CI}=.93-.98, p<.001)$ and explained $9 \%$ (Nagelkereke $R_{2}$ ) of the variance of ASD diagnosis. The results suggest that children who scored lower (raw scores) on the health and safety subscale on the Bayley®-III adaptive behavior scale are more likely to receive an ASD diagnosis than children with higher health and safety subscale raw scores.

Bayley®-III Adaptive Behavior Leisure Subscale and ASD Diagnosis Logistic regression—step $1 \mathrm{f}$ —entered the adaptive behavior leisure subscale raw scores as a predictor of ASD diagnosis. The results were statistically significant (odds ratio $=.92,95 \% \mathrm{CI}=.89-.95, p<.001)$ and explained $18 \%($ Nagelkereke $R 2)$ of the variance of ASD diagnosis. The results suggest that children who scored lower (raw scores) on the leisure subscale on the Bayley ${ }_{\circledR}$-III adaptive behavior scale are more likely to receive an ASD diagnosis than children with higher leisure subscale raw scores. 
Bayley®-III Adaptive Behavior Self-Care Subscale and ASD Diagnosis

Logistic regression—step $1 \mathrm{~g}$ - entered the adaptive behavior Self-Care subscale raw scores as a predictor of ASD diagnosis. The results were statistically significant (odds ratio $=.93,95 \% \mathrm{CI}=.90-.96, p<.001)$ and explained $13 \%\left(\right.$ Nagelkereke $\left.R_{2}\right)$ of the variance of ASD diagnosis. The results suggest that children who scored lower (raw scores) on the self-care subscale on the Bayley®-III adaptive behavior scale are more likely to receive an ASD diagnosis than children with higher self-care subscale raw scores.

\section{Bayley®-III Adaptive Behavior Self-Direction Subscale and ASD Diagnosis}

Logistic regression — step $1 \mathrm{~h}$ —entered the adaptive behavior self-direction subscale raw scores as a predictor of ASD diagnosis. The results were statistically significant (odds ratio $=.95,95 \% \mathrm{CI}=.92-.97, p<.001$ ) and explained $10 \%$ (Nagelkereke $R_{2}$ ) of the variance of ASD diagnosis. The results suggest that children who scored lower (raw scores) on the self-direction subscale on the Bayley®-III adaptive behavior scale are more likely to receive an ASD diagnosis than children with higher self-direction subscale raw scores.

\section{Bayley®-III Adaptive Behavior Social Subscale and ASD Diagnosis}

Logistic regression—step $1 \mathrm{i}$ - entered the adaptive behavior social subscale raw scores as a predictor of ASD diagnosis. The results were statistically significant (odds ratio $=.88,95 \% \mathrm{CI}=.85-.91, p<.001)$ and explained $31 \%($ Nagelkereke $R 2)$ of the variance of ASD diagnosis. The results suggest that children who scored lower (raw scores) on the social subscale on the Bayley®-III adaptive behavior scale are more likely to receive an ASD diagnosis than children with higher social subscale raw scores. 
Bayley®-III Adaptive Behavior Motor Subscale and ASD Diagnosis

Logistic regression — step $1 \mathrm{j}$ - entered the adaptive behavior motor subscale raw scores as a predictor of ASD diagnosis. The results were not statistically significant (odds ratio $=.98,95 \% \mathrm{CI}=.96-1.01, p=.14)$. Although statistical significance was not achieved, the model explained 1\% (Nagelkereke $R_{2}$ ) of the variance of ASD diagnosis. Motor subscale raw scores do not seem to vary substantially across ASD diagnostic categories. Per this sample, children with an ASD diagnosis did not appear to have significantly lower motor subscale raw scores than their non-ASD peers.

\section{Summary}

The intent of this study sought to examine the subscales that comprise the adaptive behavior section of the Bayley®-III to determine which of the ten subscales are predictive of ASD in young children (i.e., $\leq$ three years-of-age). The results found that lower standard deviation scores on the adaptive behavior scale on the Bayley ${ }^{\circledR}$-III was a statistically significant predictor of ASD in young children. Moreover, lower raw scores on the communication, community use, functional pre-academics, home living, health and safety, leisure, self-care, self-direction, and social subscales of the adaptive behavior scale of the Bayley®-III were found to be statistically significant predictors of ASD in young children. The communication and social subscales were found to contribute the greatest amount of variance in predicting ASD at $34 \%$ and $31 \%$ respectively. The tested null hypotheses are presented in Table 8.

\section{Table 8}

Summary of Tested Null Hypotheses

\begin{tabular}{|c|c|c|c|}
\hline Hypothesis & Statement & $\begin{array}{l}\text { Overall } \\
\text { Model/R2 }\end{array}$ & Result \\
\hline
\end{tabular}


There will not be a statistically significant association between autism spectrum disorder

H1 diagnosis in children $\leq$ three years-of-age and their adaptive behavior domain standard subscale score on the Bayley®-III.

The communication subscale raw score on the Bayley®-III will not significantly contribute to

H1a the variance in predicting autism spectrum disorder diagnosis in children $\leq$ three years-ofage.

The community use subscale raw score on the Bayley®-III will not significantly contribute to

H1b the variance in predicting autism spectrum disorder diagnosis in children $\leq$ three years-ofage.

The functional pre-academics subscale raw score on the Bayley®-III will not significantly

H1c contribute to the variance in predicting autism spectrum disorder diagnosis in children $\leq$ three

$.1 \% \quad$ Reject years-of-age.

The home living subscale raw score on the Bayley®-III will not significantly contribute to H1d the variance in predicting autism spectrum disorder diagnosis in children $\leq$ three years-ofage.

The health and safety subscale raw score on the Bayley®-III will not significantly contribute to

H1e the variance in predicting autism spectrum disorder diagnosis in children $\leq$ three years-of$.5 \%$ Reject age.

The leisure subscale raw score on the Bayley®-

H1f III will not significantly contribute to the variance in predicting autism spectrum disorder diagnosis in children $\leq$ three years-of-age.

The self-care subscale raw score on the Bayley®-III will not significantly contribute to

Hig the variance in predicting autism spectrum disorder diagnosis in children $\leq$ three years-ofage. 
The self-direction subscale raw score on the Bayley®-III will not significantly contribute to

Hh the variance in predicting autism spectrum $\quad 0.3 \% \quad$ Reject disorder diagnosis in children $\leq$ three years-ofage.

The social subscale raw score on the Bayley®-

Hii III will not significantly contribute to the variance in predicting autism spectrum disorder $1 \% \quad$ Reject diagnosis in children $\leq$ three years-of-age.

The motor subscale raw score on the Bayley®-

$\mathbf{H}_{\mathbf{1 j}} \quad$ III will not significantly contribute to the variance in predicting autism spectrum disorder Failed to Reject diagnosis in children $\leq$ three years-of-age. 


\section{CHAPTER 4}

\section{DISCUSSION}

The Centers for Disease Control and Prevention (CDC) reports that one in 59 children between the ages of three and four years are diagnosed with ASD crossing all racial, ethnic, and socioeconomic groups (Baio et al., 2018). However, most children are not diagnosed until after the age of four years (Developmental Disabilities Monitoring Network Surveillance Year Principal, Centers for Disease, \& Prevention, 2014). Deficits associated with ASD include impaired social communication skills as well as the presence of restricted and repetitive behaviors (American Psychiatric Association, 2013). These deficits usually present themselves in early childhood and lead to impairments in functioning across various settings (Yates \& Le Couteur, 2016). Given that these deficits are present in early childhood, it's imperative to emphasize the importance of early intervention for these individuals. Evidence suggests that the earlier a child receives intervention, the greater the likelihood of an improved developmental trajectory (Koegel et al., 2014). Early intervention has also been associated with better communicative, academic and behavioral outcomes at school-age, if implemented before the age of three (Owens, 2017). Thus, an early diagnosis is vital in order to receive the appropriate early intervention services (Koegel et al., 2014). The purpose of this study was to further examine the subscales that comprise the adaptive behavior section of the Bayley-III to determine which of the subscales are predictive of ASD in young children (i.e., $\leq$ three 
years-of-age) in hopes to contribute to the specificity of autism characteristics in early childhood as it relates to adaptive behavior.

The current study examined individual logistic regression analyses which determined that lower standard deviation scores on the adaptive behavior scale on the Bayley®-III was a statistically significant predictor of ASD in young children. Moreover, lower raw scores on the communication, community use, functional pre-academics, home living, health and safety, leisure, self-care, self-direction and social subscales were found to be statistically significant predictors of ASD in young children. The social and communication individual subscale scores contributed the greatest amount of variance when predicting the diagnosis of ASD. As these two deficits are specified within the current diagnostic criteria and there is a vast amount of literature discussing these deficits among the ASD population; these results come as no surprise.

Social and communicative deficits have been diagnostic hallmarks since the first clinical accounts of ASD were recorded (Volkmar \& Reichow, 2013). The first clinical accounts were recorded by Dr. Leo Kanner (1992) wherein he referenced difficulties with socialization among the observed group of children (Volkmar \& Reichow, 2013). Presently, one of the first symptoms that is commonly found in children with ASD is their lack of social interaction (Miskam et al., 2014). Studies examining the relationship between communication skills and corresponding levels of adaptive behavior in individuals with ASD are limited (Kjellmer, Hedvall, Fernell, Gillberg, \& Norrelgen, 2012). However, Kjellmer et al. (2012) concluded that non-verbal communication skills may be related to severity of autism symptoms as well as adaptive functioning. Further, 
Owens (2017), lists the common autism symptoms related to social-communication. These include:

"Abnormal social interactions and difficulty adjusting to different social situations; abnormal reaction to and difficulty integrating sensory information such as verbal and nonverbal aspects of communication; difficulty with the giveand-take of conversation; and poorly integrated verbal and nonverbal communication, including poor eye contact and body language, echolalia or repetition of others' speech, and repetition of certain expressions" (Owens, 2017, p. 32).

The lack of communication skills displayed by children with autism are the greatest cause of concern for parents (Owens, 2017). As limited communication skills are associated with ASD, these individuals are more likely to display challenging behaviors and/or aggression as this may be their only means of communication, indirectly resulting in increased parental psychological distress (Salomone, The C. S. T. Italy Team, Settanni, Ferrara, \& Salandin, 2019). One study examined how parents modified the environment in order to meet the needs of their child with ASD who demonstrated challenging behaviors (Elizabeth, Francesca, Kris, Hannah, \& Ilse, 2017). The study revealed that parents limited social activities and outings with the child (i.e., shopping, visiting restaurants) (Elizabeth et al., 2017). Further, parents avoided taking their child to new and different environments, limiting their exposure into the community (Elizabeth et al., 2017).

The community-use and home-living subscales of the Bayley-III measure a child's ability to participate in activities and interests throughout the community as well 
as completing household tasks and taking care of personal possessions. (Bayley, 2006). According to parent interviews, factors contributing to decreased community and home participation include, but are not limited to, displaying tantrums in community settings as well as demonstrating difficulty with following directions (LaVesser \& Berg, 2011).

One study examined participation patterns in preschool children with ASD, specifically within the domains of community mobility and domestic chores (LaVesser \& Berg, 2011). The results indicated that children with ASD participate in significantly fewer activities in all domains compared to typically developing children (LaVesser \& Berg, 2011). Further, the presence of restricted and repetitive behaviors (RRBs) have been shown to set these individuals apart resulting in increased risk for reduced participation in everyday activities (LaVesser \& Berg, 2011). Behaviors included in the category of RRBs are:

"repetitive motor mannerisms (i.e. hand flapping); persistent occupation with parts of objects (i.e. spinning wheels on toy car); encompassing preoccupations/restricted patterns of interest (i.e. an intense interest in trains); and inflexible adherence to nonfunctional routines/rituals (i.e. insisting that items are arranged on the dinner table in a precise way)" (Richler, Bishop, Kleinke, \& Lord, 2007, pp. 73-74).

Liss et al. (2001) studied individuals with ASD as they completed the Wisconsin Card Sorting Task (WCST) and found these individuals participating in perseverative behaviors throughout the task, affecting their accuracy and completion. Whereas this task was completed for an experimental purpose, it can emphasize the role repetitive and 
perseverative behaviors play on the accuracy and completion of everyday tasks such as domestic chores and self-care routines (South, Ozonoff, \& McMahon, 2007)

Moreover, the presence of restricted and repetitive behaviors most clearly related to deficits in executive function (Griffith, Pennington, Wehner, \& Rogers, 1999). In a study conducted by Pennington and Ozonoff (1996), individuals with autism completed executive functioning tasks with a higher number of perseverative errors as well as exhibited rigid and inflexible problem-solving strategies.

Executive functioning (EF) closely pertains to the cognitive domains of attention, reasoning and problem-solving (Pennington \& Ozonoff, 1996). Particularly, "set-shifting and set-maintenance, interference control, inhibition, integration across space and time, planning, and working memory" are that of a few executive functions (Pennington \& Ozonoff, 1996, p. 55). Liss et al. (2001) further included the processes of "forming abstract concepts, having a flexible sequenced plan of action, focusing and sustaining attention and mental effort, rapidly retrieving relevant information, being able to selfmonitor and self-correct as a task is performed, and being able to inhibit impulsive responses" as EF components (p. 261). An individual's level of executive functioning has been shown to correlate with academic skills (Liss et al., 2001). Wenz-Gross, Yoo, Upshur, and Gambino (2018) affirms that EF comprises of "cognitive processes thought to support academic achievement through top down control of attention and behavior" ( $\mathrm{p}$. 2). In general, learning is characterized by the executive functioning tasks of "seeing relationships between pieces of information, identifying central patterns or themes, distinguishing relevant from irrelevant information, and deriving meaning" (Pennington \& Ozonoff, 1996, p. 70). As it relates to the present study, the functional pre-academic 
domain within the Bayley-III assesses pre-academic skills such as letter recognition, counting and drawling simple shapes (Bayley, 2006). The results of this study can be explained by the theory of executive dysfunction, as it is known that individuals with ASD display difficulties with EF as it pertains to academic skills (Pennington \& Ozonoff, 1996). Conceptual understanding of the main idea or big picture of a topic is often lacking among this group of individuals (Pennington \& Ozonoff, 1996). Lopez, Lincoln, Ozonoff, and Lai (2005), state that individuals with ASD exhibit difficulties to "execute mental control necessary for maintaining a problem-solving strategy to obtain a future goal" as well as deficits in cognitive flexibility and planning (p. 445).

The self-care and health and safety domains encompass the skills used in order to complete functional tasks of daily living in addition to the ability to complete those tasks safely and avoid physical dangers (Bayley, 2006). Cavkaytar and Pollard (2009) report that many individuals with autism require multiple repetitions of instructions and demonstrate deficits in independently completing daily living skills. One study explored possible reasons for these deficits and included the following; lack of motivation, habits/performance patterns, communication abilities, sensory processing difficulties and variability in performance (Kern, Wakeford, \& Aldridge, 2007). Individuals with autism may not find the value in the self-care task itself nor its outcome and are unlikely to become motivated to finish the task merely to "please an adult or conform to social standards" (Kern et al., 2007, p. 44). With these individuals demonstrating perseverative and stereotyped behaviors, this population tends to stick to strict rituals and routines (American Psychiatric Association, 2013). Therefore, incorporating new routines to complete tasks of daily living may be difficult to an individual with autism (Kern et al., 
2007). Additionally, difficulty understanding the task at hand and the inability for the child to express his/her own needs can affect the completion and/or accuracy of said task (Kern et al., 2007).

Additionally, it is common for individuals with autism to demonstrate difficulties regarding sensory processing (Rogers, Hepburn, \& Wehner, 2003). Sensory difficulties may interfere in with self-care tasks in a number of ways, one of which being unable to teach the child the self-care task (Kern et al., 2007). Hand-over-hand assistance will likely be resisted by the child with sensory processing deficits (Kern et al., 2007). Lastly, a variability in performance demonstrated by the child and the inconsistencies of adult responses can influence both "task performance and trajectories of progress" in the realm of completing tasks of daily living (Kern et al., 2007, p. 44).

The self-direction and leisure subscales pertain to skills such as self-control, following directions and rules, making choices, playing, and participating in recreational activities within the home (Bayley, 2006). A study conducted by Bachevalier and Loveland (2006) found that individuals with ASD demonstrated difficulties with selfregulation of social emotional behavior. Self-regulation is defined in the aforementioned study as "the ability to select and initiate complex behaviors in response to the specific condition of the social environment" (Bachevalier \& Loveland, 2006, p. 98). The ability to self-regulate depends greatly on making inferences about the people and the environment surrounding one's self (Bachevalier \& Loveland, 2006). With these individuals demonstrating deficits in social communication and social-emotional behavior, self-regulation then becomes difficult (Bachevalier \& Loveland, 2006; Juergensen et al., 2018). The results of an additional study concluded that children with 
autism had significant deficits in the "stability of self-regulation and affective expression" as compared to that in individuals with Down syndrome (Bieberich \& Morgan, 2004, p. 439). Further, with measures assessing attention, flexibility, engagement and goal-directedness during play activities, individuals with ASD demonstrated greater deficits within these realms relative to the group of individuals with Down syndrome (Bieberich \& Morgan, 2004). More specifically, the ASD group exhibited difficulties in the ability to sustain attention and concentration to facilitate appropriate play activity (Bieberich \& Morgan, 2004).

When examining the participation patterns in preschool-aged children with autism, parent interviews revealed children with ASD participate in fewer preschool activities of vigorous leisure (LaVesser \& Berg, 2011). Specific factors affecting decreased participation in leisure include, but are not limited to, the child's inability to follow directions as well as the child's disinterest in the leisure activity (LaVesser \& Berg, 2011).

The motor component assesses a child's locomotive abilities as well as his/her ability to manipulate his/her environment (Bayley, 2006). Contrarily, the motor subscale raw score on the Bayley®-III did not significantly contribute to the variance in predicting autism spectrum disorder diagnosis in children $\leq$ three years-of-age. Presently, the literature is mixed on whether or not motor deficits are a diagnostic characteristic of ASD. Within various studies examining motor coordination, arm movements, gait, and postural stability deficits, individuals with ASD were found to have significant deficits among these motor domains (Fournier, Hass, Naik, Lodha, \& Cauraugh, 2010). Likewise, difficulties with postural control, fine and gross motor coordination and gait 
abnormalities have been shown to co-occur with an ASD diagnosis (Mody et al., 2017). However, in contrast to the aforementioned literature, Ming, Brimacombe, and Wagner (2007) found no significant association between a diagnosis of ASD and motor deficits. Furthermore, within this study, only 14 children (9\%) among the sample group had a history of a gross motor delay and all 14 of these children achieved gross motor milestones by the enrollment of the study (Ming et al., 2007). Additionally, Hanaie et al. (2014) investigated the relationship between abnormal Corpus Callosum (CC) connectivity and its effect on socio-communicative and motor deficits in children with ASD. This study displayed abnormal CC connectivity relative to socio-communicative deficits but not as it related to motor deficits in children with ASD (Hanaie et al., 2014). Previously, a study was conducted examining a predictive relationship between the five main developmental domains within the Bayley-III assessment and a diagnosis of ASD (Juergensen et al., 2018). The results indicated that the motor standard deviation subscale were not significant as an individual predictor of an ASD diagnosis, supportive of the present study's findings (Juergensen et al., 2018).

Several factors within this study pose possible limitations. The adaptive behavior portion of the Bayley-III is assessed based on a questionnaire that is to be filled out by the child's parent, guardian and/or clinician. This could result in biased data and understanding of the participants. In this case, self-reporting bias may be present (Althubaiti, 2016). Self-reporting is a common approach utilized by researchers to obtain data (Althubaiti, 2016). Examples of self-reporting include questionnaires, surveys or interviews (Althubaiti, 2016). Two different types of bias can result from self-reportingsocial desirability bias and recall bias (Althubaiti, 2016). When researchers use self- 
reporting as a means of data collection, the questions asked may concern private or sensitive topics, in this case, questions were asked regarding the child of the participants development (Althubaiti, 2016). Thus, answers to these questions can be "affected by an external bias caused by social desirability or approval" (Althubaiti, 2016, p. 212). Further, self-reporting measures may require participants to recall past events (Althubaiti, 2016). Participants may provide errors in this response and result in a recall error (Althubaiti, 2016).

Additionally, the evaluation and diagnostic processes for early intervention vary by state. This study obtained files and data from Kentucky's early intervention program - First Steps (Kentucky Cabinet for Health and Family Services, 2017). Other states may have different protocols and procedures in place when assessing children three years of age and younger for autism. There are various tools available to early interventionists for the assessment of children three years of age and younger. This study utilized results from the Bayley-III due to availability. While this is a popular tool utilized by early interventionists, opportunities for future research can include results from other standardized assessments.

Currently, the literature regarding motor deficits within this population is varied and limited. Future research among this realm will allow for increased specificity in motor characteristics in young children with ASD. As previously mentioned, future research can incorporate other popular assessment tools to examine the different domains and determine if they are predictive of an autism diagnosis. This can allow for a more descriptive analysis of early diagnostic characteristics of autism in young children. 
The intent of this study was primarily to contribute to the specificity of early diagnostic characteristics in young children with ASD. More specifically, the study's focus was on the diagnostic characteristics relative to that of adaptive behavior skills. The study encompassed children three years of age and younger. The findings were consistent with the current body of literature on ASD with respect to deficits in social, communication, functional pre-academics, leisure, self-care, self-direction, health \& safety, home-living, and community use (Bachevalier \& Loveland, 2006; Cavkaytar \& Pollard, 2009; Juergensen et al., 2018; Kern et al., 2007; LaVesser \& Berg, 2011; Liss et al., 2001; Pennington \& Ozonoff, 1996; Volkmar \& Reichow, 2013)

It is the researchers' belief that with increased knowledge of ASD characteristics in young children there will be an increase in a definitive ASD diagnosis at an earlier age. Concurrently, this will allow for these individuals and their families to benefit from early intervention services which have been shown to greatly improve the individual's developmental trajectory. It is our hope that the limited knowledge base on early ASD diagnosis in young children has been increased and the gap in the available literature narrowed. 


\section{REFERENCES}

Al-Hamdan, A. Z., Preetha, P. P., Albashaireh, R. N., Al-Hamdan, M. Z., \& Crosson, W. L. (2018). Investigating the effects of environmental factors on autism spectrum disorder in the USA using remotely sensed data. Environmental Science and Pollution Research, 25(8), 7924-7936. doi:10.1007/s11356-017-1114-8

Althubaiti, A. (2016). Information bias in health research: definition, pitfalls, and adjustment methods. Journal of Multidisciplinary Healthcare, 211. doi:10.2147/JMDH.S104807

American Psychiatric Association. (1985). Diagnostic and Statistical Manual of Mental Disorders (3rd ed.). Washington, D.C. : The American Psychiatric Association

American Psychiatric Association. (1994). Diagnostic and Statistical Manual of Mental Disorders (4th ed.). Washington, DC: American Psychiatric Publishing

American Psychiatric Association. (2013). Diagnostic and Statistical Manual for Mental Disorders (5th ed.). Washington DC: American Psychiatric Publishing

American Speech-Language-Hearing Association. Early Intervention: Overview Retrieved from https://www.asha.org/PRPSpecificTopic.aspx?folderid=8589943999\&section=Ov erview

Babyak, M. A. (2004). What you see may not be what you get: a brief, nontechnical introduction to overfitting in regression-type models. Psychosomatic medicine, 66(3), 411-421.

Bachevalier, J., \& Loveland, K. A. (2006). The orbitofrontal-amygdala circuit and selfregulation of social-emotional behavior in autism. Neuroscience and Biobehavioral Reviews, 30(1), 97-117. doi:10.1016/j.neubiorev.2005.07.002

Baio, J., Wiggins, L., Christensen, D. L., Maenner, M. J., Daniels, J., Warren, Z., . . . Dowling, N. F. (2018). Prevalence of Autism Spectrum Disorder Among Children Aged 8 Years - Autism and Developmental Disabilities Monitoring Network, 11 Sites, United States, 2014. Morbidity and mortality weekly report. Surveillance summaries (Washington, D.C. : 2002), 67(6), 1-23. doi:10.15585/mmwr.ss6706a1

Barbeau, W. E. (2017). Neonatal and regressive forms of autism: Diseases with similar symptoms but a different etiology. Medical Hypotheses, 109, 46-52. doi:10.1016/j.mehy.2017.09.015

Bayley, N. (2006). Bayley scales of infant and toddler development (3rd ed.). San Antonio, TX Harcourt Assessment Inc.

Bieberich, A. A., \& Morgan, S. B. (2004). Self-Regulation and Affective Expression During Play in Children with Autism or Down Syndrome: A Short-Term Longitudinal Study. Journal of autism and developmental disorders, 34(4), 439448. doi:10.1023/B:JADD.0000037420.16169.28 
Bölte, S., Girdler, S., \& Marschik, P. B. (2019). The contribution of environmental exposure to the etiology of autism spectrum disorder. Cellular and molecular life sciences : CMLS, 76(7), 1275-1297. doi:10.1007/s00018-018-2988-4

Cavkaytar, A., \& Pollard, E. (2009). Effectiveness of Parent and Therapist Collaboration Program (PTCP) for Teaching Self-Care and Domestic Skills to Individuals with Autism. Education and Training in Developmental Disabilities, 44(3), 381-395.

Crais, E. R. (2011). Testing and beyond: strategies and tools for evaluating and assessing infants and toddlers. Language, speech, and hearing services in schools, 42(3), 341-364. doi:10.1044/0161-1461(2010/09-0061)

Developmental Disabilities Monitoring Network Surveillance Year Principal, I., Centers for Disease, C., \& Prevention. (2014). Prevalence of autism spectrum disorder among children aged 8 years - autism and developmental disabilities monitoring network, 11 sites, United States, 2010. Morbidity and mortality weekly report. Surveillance summaries (Washington, D.C. : 2002), 63(2), 1-21.

Elizabeth, O. N., Francesca, H., Kris, E., Hannah, B., \& Ilse, N. (2017). How do Parents Manage Irritability, Challenging Behaviour, Non-Compliance and Anxiety in Children with Autism Spectrum Disorders? A Meta-Synthesis. Journal of autism and developmental disorders, 1-15. doi:10.1007/s10803-017-3361-4

Fournier, K. A., Hass, C. J., Naik, S. K., Lodha, N., \& Cauraugh, J. H. (2010). Motor Coordination in Autism Spectrum Disorders: A Synthesis and Meta-Analysis. Journal of autism and developmental disorders, 40(10), 1227-1240. doi:10.1007/s10803-010-0981-3

Griffith, E. M., Pennington, B. F., Wehner, E. A., \& Rogers, S. J. (1999). Executive Functions in Young Children with Autism. Child Development, 70(4), 817-832.

Hanaie, R., Mohri, I., Kagitani-Shimono, K., Tachibana, M., Matsuzaki, J., Watanabe, Y., . . Taniike, M. (2014). Abnormal corpus callosum connectivity, sociocommunicative deficits, and motor deficits in children with autism spectrum disorder: a diffusion tensor imaging study. Journal of autism and developmental disorders, 44(9), 2209-2220. doi:10.1007/s 10803-014-2096-8

Harrison, P., \& Oakland, T. (2003). Adaptive Behavior Assessment System (2nd ed.). Los Angeles, CA: Western Psychological Services

Johnson, C. P., Myers, S. M., \& American Academy of Pediatrics Council on Children With, D. (2007). Identification and evaluation of children with autism spectrum disorders. Pediatrics, 120(5), 1183-1215.

Juergensen, K., Smith, A., Mattingly, R., \& Pitts, T. (2018). Autism Spectrum Disorder: Investigating predictive diagnostic relationships in children three years-of-age and younger University of Louisville

Kanne, S. M., Gerber, A. J., Quirmbach, L. M., Sparrow, S. S., Cicchetti, D. V., \& Saulnier, C. A. (2011). The Role of Adaptive Behavior in Autism Spectrum Disorders: Implications for Functional Outcome. Journal of autism and developmental disorders, 41(8), 1007-1018.

Kanner, L. (1943). Autistic Disturbances of Affective Contact. Nervous Child, 2, 217 250.

Kanner, L. (1971). Follow-up study of eleven autistic children originally reported in 1943. Journal of autism and childhood schizophrenia, 1(2), 119-145. 
Kanner, L. (1992). Follow-up Study of Eleven Autistic Children Originally Reported in 1943. Focus on Autistic Behavior, 7(5), 1-11. doi:10.1177/108835769200700501

Kentucky Cabinet for Health and Family Services. (2017). Early Childhood Development Branch; First Steps Retrieved from https://chfs.ky.gov/agencies/dph/dmch/ecdb/Pages/firststeps.aspx

Kern, P., Wakeford, L., \& Aldridge, D. (2007). Improving the Performance of a Young Child with Autism during Self-Care Tasks Using Embedded Song Interventions: A Case Study. Music Therapy Perspectives, 25(1), 43-51. doi:10.1093/mtp/25.1.43

Kjellmer, L., Hedvall, А., Fernell, E., Gillberg, C., \& Norrelgen, F. (2012). Language and communication skills in preschool children with autism spectrum disorders: Contribution of cognition, severity of autism symptoms, and adaptive functioning to the variability. Research in Developmental Disabilities, 33(1), 172-180. doi:10.1016/j.ridd.2011.09.003

Koegel, L. K., Koegel, R. L., Ashbaugh, K., \& Bradshaw, J. (2014). The importance of early identification and intervention for children with or at risk for autism spectrum disorders. International journal of speech-language pathology, 16(1), 50-56. doi:10.3109/17549507.2013.861511

Kraemer, H. C., \& Blasey, C. M. (2004). Centring in regression analyses: a strategy to prevent errors in statistical inference. International Journal of Methods in Psychiatric Research, 13(3), 141-151. doi:10.1002/mpr.170

LaVesser, P., \& Berg, C. (2011). Participation patterns in preschool children with an autism spectrum disorder. OTJR Occupation, Participation and Health, 31(1), 3339. doi:10.3928/15394492-20100823-01

Liss, M., Fein, D., Allen, D., Dunn, M., Feinstein, C., Morris, R., . . Rapin, I. (2001). Executive Functioning in High-functioning Children with Autism. Journal of Child Psychology and Psychiatry, 42(2), 261-270. doi:10.1111/1469-7610.00717

Lopez, B., Lincoln, A., Ozonoff, S., \& Lai, Z. (2005). Examining the Relationship between Executive Functions and Restricted, Repetitive Symptoms of Autistic Disorder. Journal of autism and developmental disorders, 35(4), 445-460.

Matson, J. L., Wilkins, J., \& Fodstad, J. C. (2010). Children with autism spectrum disorders: a comparison of those who regress vs. those who do not. Developmental neurorehabilitation, 13(1), 37-45. doi:10.3109/17518420903107984

Ming, X., Brimacombe, M., \& Wagner, G. C. (2007). Prevalence of motor impairment in autism spectrum disorders. Brain and Development, 29(9), 565-570. doi:10.1016/j.braindev.2007.03.002

Miskam, M. A., Masnin, N. F. S., Jamhuri, M. H., Shamsuddin, S., Omar, A. R., \& Yussof, H. (2014). Encouraging Children with Autism to Improve Social and Communication Skills through the Game-based Approach. Procedia Computer Science, 42, 93-98. doi:10.1016/j.procs.2014.11.038

Mody, M., Shui, A. M., Nowinski, L. A., Golas, S. B., Ferrone, C., O’Rourke, J. A., \& McDougle, C. J. (2017). Communication Deficits and the Motor System: Exploring Patterns of Associations in Autism Spectrum Disorder (ASD). Journal 
of autism and developmental disorders, 47(1), 155-162. doi:10.1007/s10803-0162934-y

Mukaka, M. M. (2012). Statistics corner: A guide to appropriate use of correlation coefficient in medical research. Malawi medical journal : the journal of Medical Association of Malawi, 24(3), 69-71.

Owens, R. (2017). Early Language Intervention for Infants, Toddlers, and Preschoolers. New York, New York Pearson

Pasco, G. (2018). The value of early intervention for children with autism. Paediatrics and Child Health, 28(8), 364-367. doi:10.1016/j.paed.2018.06.001

Pennington, B. F., \& Ozonoff, S. (1996). Executive Functions and Developmental Psychopathology. Journal of Child Psychology and Psychiatry, 37(1), 51-87. doi:10.1111/j.1469-7610.1996.tb01380.x

Phung, J. N., \& Goldberg, W. A. (2019). Promoting Executive Functioning in Children with Autism Spectrum Disorder Through Mixed Martial Arts Training. Journal of autism and developmental disorders, 49(9), 3669-3684. doi:10.1007/s10803-01904072-3

Pugliese, C. E., Anthony, L., Strang, J. F., Dudley, K., Wallace, G. L., \& Kenworthy, L. (2015). Increasing Adaptive Behavior Skill Deficits From Childhood to Adolescence in Autism Spectrum Disorder: Role of Executive Function. Journal of autism and developmental disorders, 45(6), 1579-1587. doi:10.1007/s10803014-2309-1

Ratto, A. B., Kenworthy, L., Yerys, B. E., Bascom, J., Wieckowski, A. T., White, S. W., . .. Anthony, L. G. (2018). What About the Girls? Sex-Based Differences in Autistic Traits and Adaptive Skills. Journal of autism and developmental disorders, 48(5), 1698-1711. doi:10.1007/s10803-017-3413-9

Raver, S. A., \& Childress, D. C. (2015). Family-centered early intervention: Supporting infants and toddlers in natural environments Baltimore, MD: Brookes.

Richler, J., Bishop, S., Kleinke, J., \& Lord, C. (2007). Restricted and Repetitive Behaviors in Young Children with Autism Spectrum Disorders. Journal of autism and developmental disorders, 37(1), 73-85.

Rogers, S. J. (1996). Brief Report: Early Intervention in Autism. Journal of autism and developmental disorders, 26(2), 243-246.

Rogers, S. J. (2004). Developmental regression in autism spectrum disorders. Mental Retardation and Developmental Disabilities Research Reviews, 10(2), 139-143. doi:10.1002/mrdd.20027

Rogers, S. J., Hepburn, S., \& Wehner, E. (2003). Parent Reports of Sensory Symptoms in Toddlers with Autism and Those with Other Developmental Disorders. Journal of autism and developmental disorders, 33(6), 631-642. doi:10.1023/B:JADD.0000006000.38991.a7

Salomone, E., The C. S. T. Italy Team, Settanni, M., Ferrara, F., \& Salandin, A. (2019). The Interplay of Communication Skills, Emotional and Behavioural Problems and Parental Psychological Distress. Journal of autism and developmental disorders, 49(11), 4365-4374. doi:10.1007/s 10803-019-04142-6

South, M., Ozonoff, S., \& McMahon, W. M. (2007). The relationship between executive functioning, central coherence, and repetitive behaviors in the high-functioning 
autism spectrum. Autism : the international journal of research and practice, 11(5), 437-451.

Tabachnick, B. G., \& Fidell, L. S. (2013). Using Multivariative Statistics (6th edition ed.). Harlow, England: Pearson.

U.S. Department of Education. (2004). Individuals with Disabilities Education Act Washington, DC: U.S. Government Printing Office

Volkmar, F. R., \& Reichow, B. (2013). Autism in DSM-5: progress and challenges. Molecular autism, 4(1), 13. doi:10.1186/2040-2392-4-13

Warner, R. M. (2013). Applied Statistics: From Bivariate Through Multivariate Techniques (2nd Edition ed.). Newbury, California: SAGE

Wenz-Gross, M., Yoo, Y., Upshur, C. C., \& Gambino, A. J. (2018). Pathways to Kindergarten Readiness: The Roles of Second Step Early Learning Curriculum and Social Emotional, Executive Functioning, Preschool Academic and Task Behavior Skills. Frontiers in psychology, 9, 1886. doi:10.3389/fpsyg.2018.01886

Werner, E., Dawson, G., Munson, J., \& Osterling, J. (2005). Variation in Early Developmental Course in Autism and its Relation with Behavioral Outcome at 34 Years of Age. Journal of autism and developmental disorders, 35(3), 337-350. doi:10.1007/s10803-005-3301-6

White, E. I., Wallace, G. L., Bascom, J., Armour, A. C., Register-Brown, K., Popal, H. S., . . Kenworthy, L. (2017). Sex differences in parent-reported executive functioning and adaptive behavior in children and young adults with autism spectrum disorder. Autism Research, 10(10), 1653-1662. doi:10.1002/aur.1811

Wong, C. T., Wais, J., \& Crawford, D. A. (2015). Prenatal exposure to common environmental factors affects brain lipids and increases risk of developing autism spectrum disorders. European Journal of Neuroscience, 42(10), 2742-2760. doi:10.1111/ejn.13028

Xu, G., Strathearn, L., Liu, B., \& Bao, W. (2018). Prevalence of Autism Spectrum Disorder Among US Children and Adolescents, 2014-2016. JAMA, 319(1), 81-82. doi:10.1001/jama.2017.17812

Yates, K., \& Le Couteur, A. (2016). Diagnosing autism/autism spectrum disorders. Paediatrics and Child Health, 26(12), 513-518. doi:10.1016/j.paed.2016.08.004 


\section{APPENDIX: ABBREVIATIONS}

ASD

AUC

Bayley-III Bayley Scales of Infant and Toddler Development, 3rd Edition

$\mathrm{CC}$

CDC

CI

COM

$\mathrm{CU}$

DSM-III

DSM-IV

DSM-V

$\mathrm{EF}$

FA

HL

HS

IDEA

ILE

IRB

LS

Autism Spectrum Disorder

Area Under the Curve

Corpus Callosum

Center for Disease Control and Prevention

Confidence Interval

Communication

Community Use

Diagnostic Statistical Manual of Mental Disorders, 3rd Edition

Diagnostic Statistical Manual of Mental Disorders, 4th Edition

Diagnostic Statistical Manual of Mental Disorders, 5th Edition

Executive Function

Functional Pre-Academics

Home Living

Health and Safety

Individuals with Disabilities Education Act

Intensive Level of Evaluation

Institutional Review Board

Leisure 


$\begin{array}{ll}\text { MO } & \text { Motor } \\ \text { PDD } & \text { Pervasive Developmental Disorder } \\ \text { PDD-NOS } & \text { Pervasive Developmental Disorder-Not Otherwise Specified } \\ \text { RRB } & \text { Restrictive and Repetitive Behaviors } \\ \text { SC } & \text { Self-Care } \\ \text { SD } & \text { Self-Direction } \\ \text { SOC } & \text { Social } \\ \text { SPSS } & \text { Statistical Package for Social Sciences } \\ \text { TOTS } & \text { Technology - assisted Observation and Teaming Support } \\ \text { WCEC } & \text { Weisskopf Child Evaluation Center } \\ \text { WCST } & \text { Wisconsin Card Sorting Task }\end{array}$




\section{CURRICULUM VITAE}

NAME:

ADDRESS:

DOB:

EDUCATION

\& TRAINING:
Emma Louise Feige

Department of Communicative Disorders

Speech-Language Pathology

MDA Building School of Medicine

627 S. Preston St., Suite 620

University of Louisville

Louisville, KY 40292

Louisville, KY - January 14, 1996

B.S., Communication Sciences and Disorders

Western Kentucky University

2014-2018

M. S., Communicative Disorders

University of Louisville

2018-2020
PROFESSIONAL SOCIETIES:
National Student Speech Language Hearing Association University of Louisville, Louisville, KY

August 2018 - present

Kentucky Speech-Language-Hearing Association August 2018 - present

PRESENTATIONS: Feige, E., Mattingly, R., Pitts, T., \& Smith, A. (2020). Autism Spectrum Disorder: Investigating Predictive Adaptive Behavior Skill Deficits in Young Children. Poster presentation at the Kentucky Speech-Language-Hearing Association annual meeting, February 20, 2020 Lexington, KY. 